Volume III, No.1 Juni 2013/1434 H

\title{
PENGARUH RELIGIUSITAS TERHADAP PERILAKU BERAMAL (CHARITABLE BEHAVIOR) MASYARAKAT KOTA YOGYAKARTA
}

\author{
Sri Maulida \\ (Sekolah Tinggi Ekonomi Islam Yogyakarta)
}

\begin{abstract}
The aim of this research is to know the effect of religiosity on charitable behavior at the society of Yogyakarta City. The charitable behavior in this research is the concept from Islam paradigm e.g. Zakat, Infak, Sadaqah and Waqf. This research is field research by using a quantitative approach. The population of this research is all people at Yogyakarta City. It used judgment sampling method with a sample of 100 Moslem respondents at Yogyakarta City, and it used simple regression techniques to analyze the data. Variables such as religiosity, intrinsic religiosity, extrinsic religiosity and Islamic doctrine are studied by their potency to influence the charitable behavior at Yogyakarta.
\end{abstract}

Keywords: religiosity, charitable behavior.

\section{A. Pendahuluan}

a. Perilaku beramal di Indonesia

Perilaku masyarakat dalam menyumbang atau beramal (charitable behavior) mengalami penurunan di Indonesia. Salah satu survei yang dilakukan PIRAC (Public Interest Research and Advocacy Center) mengenai pola dan potensi sumbangan masyarakat di 11 kota besar di Indonesia pada tahun 2000, 2004 dan 2007. Seperti survei sebelumnya, jenis sumbangan masyarakat dalam survei ini dibagi dalam tiga katagori, yakni sumbangan individu, sumbangan keagamaan dan sumbangan non keagamaan. Hasil survei 2007 menunjukkan dari ketiga jenis sumbangan masyarakat, sumbangan keagamaan secara prosentase dan jumlah rata-rata sumbangan masyarakat serta dilihat dari jumlah dana yang diberikan mengalami penurunan yaitu dari Rp483.241 per orang per tahun menjadi Rp334.850 per orang per tahun (PIRAC, 2007).

Mayoritas penduduk di Indonesia adalah Muslim dengan jumlah populasi sebesar 207.176 .162 jiwa $(87,18 \%)$ dari total penduduk Indonesia sebesar 237.641.326 jiwa (www.sp2010.bps.go.id). Sebagai mayoritas seharusnya dengan keyakinan agama yang dimiliki, umat Muslim memiliki kontribusi yang nyata terhadap pengembangan perilaku beramal 
di Indonesia. Namun, dengan konsep dan potensi sumbangan di Indonesia umat Muslim masih belum dapat memberikan kontribusi yang maksimal untuk pengembangan tersebut, sehingga masalah tersebut masih menjadi masalah serius di Indonesia khususnya di kalangan internal umat Muslim.

Islam mengajarkan perilaku beramal dalam empat cara yaitu zakat, infak, shadaqah, dan wakaf. Perilaku beramal dalam bentuk shadaqah dapat dibagi menjadi materi dan non materi, namun dalam penelitian ini penyusun membatasi hanya pada shadaqah dan wakaf materi atau berupa uang.

Faktor religiusitas akan berkembang dengan baik dengan lingkungan dan budaya yang mendukung seperti jumlah penduduk umat Muslim suatu daerah dan kebudayaan agamanya. Kota Yogyakarta adalah salah satu kota bersejarah di Pulau Jawa dan sekaligus tempat kedudukan bagi Sultan Yogyakarta dan Adipati Pakualaman. Jumlah penduduk Muslim Kota Yogyakarta berdasarkan sensus penduduk tahun 2010 berjumlah 323.433 jiwa atau sekitar $90 \%$ yang mayoritas memeluk agama Islam sehingga menjadikan Kota Yogyakarta menjadi kota yang kental dengan budaya Islam (www.sp2010.bps.go.id). Namun pada tahun 2012 dalam penyerapan potensi perilaku beramal, kota Yogyakarta masih menyerap 30 persen dari total potensi yang ada seperti yang dikatakan Kepala Staf Sekretariat Badan Amil Zakat Nasional (Baznas) Kota Yogyakarta, Misbachrudin (www.ramadhan.antaranews.com)

\section{b. Faktor-faktor yang Berhubungan dengan Perilaku Beramal}

Weaver dan Agle (2002) telah menunjukkan bahwa religiusitas mempunyai hubungan terhadap perilaku dan sikap manusia (dalam Youssef et al.,2011). Berdasarkan model Hunt-Vitell (1986, 1992), religiusitas merupakan salah satu dari elemen-elemen pribadi yang utama yang tertanam dalam karakter manusia. Identitas pribadi yang bersifat religius mempunyai dampak terhadap perilaku, dan hal ini dibentuk dari ekspektasi peran yang ditawarkan dan ditentukan oleh agama (Vitell et al., 2005). Religiusitas memiliki kekuatan untuk mengendalikan keyakinan dan juga perilaku (Light et al., 1989). Dimensi teologis menyangkut moral merupakan kekuatan khas yang memotivasi tindakan manusia, dan dimensi ini menyediakan motivasi untuk tindakan bermoral. Singh (2001) menyatakan hal tersebut dengan melihat berbagai kitab suci agama, bukubuku, dan ajaran-ajaran. Ada satu hal yang akan didapat dari itu semua, yaitu bahwa semua agama benar-benar memotivasi perilaku bermoral dan moralitas tersebut berpengaruh terhadap perilaku masyarakat dan juga dalam pengambilan keputusan. Religiusitas merupakan tingkat keterkaitan sesorang terhadap agama yang dianutnya. Religiusitas meliputi pengetahuan agama, pengalaman ritual agama, pengalaman agama, perilaku (moralitas) agama dan sikap sosial keagamaan sikap sosial kegamaan dapat di terapkan dengan cara melakukan amal (charitable behavior) sehingga religiusitas dapat dipercaya mendorong perilaku beramal seseorang, penyusun mengasumsikan bahwa religiusitas berhubungan erat dengan perilaku beramal seseorang (dalam Youssef et al.,2011).

Perilaku beramal (Charitable behavior) adalah aktivitas yang timbul karena adanya stimulus atau rangsangan yang berasal dari luar maupun 
dari dalam dirinya dengan respon memberikan bantuan kepada masyarakat yang membutuhkan. Perilaku beramal dapat diukur dengan konsep beramal yang diproksikan dalam jumlah rupiah yang digunakan responden untuk beramal (Alawiyah:2009), intensitas responden dalam beramal (Machrus dan Purwono: 2010) dan teori bentuk-bentuk perilaku beramal dalam Islam yaitu: zakat, infak, sadaqah, dan wakaf (Veen, 2009 ; Lambaraa dan Riener, 2012 ; Martens, 2010; Qardhawi: 1997).

\section{B. Metode}

\section{a. Data dan Sampel}

Teknik pengumpulan data yang digunakan dalam penelitian ini menggunakan kuesioner atau angket. Angket adalah sejumlah pertanyaan tertulis yang digunakan untuk memperoleh informasi dari responden dalam arti laporan tentang pribadinya atau hal yang diketahuinya. Untuk mendapatkan data tentang pengaruh religiusitas terhadap perilaku beramal, maka penyusun menyebarkan angket terhadap responden yang dijadikan sampel. Angket disebar ke 100 responden yang terdiri dari 14 kecamatan di kota Yogyakarta. Dalam penelitian ini metode pengambilan sample menggunakan judgement sampling. Judgement sampling adalah penarikan sampel dengan pertimbangan tertentu. Peneliti menggunakan pertimbangan tertentu untuk memilih anggota sampel yang sekiranya dapat memberikan prospek yang baik bagi pengolahan data yang akurat. Sampel yang dipilih berdasarkan kriteria responden harus merupakan seorang muslim dan adalah kepala keluarga yang memiliki hak dalam proses pengambilan keputusan dalam keluarganya (dapat mencakup suami, istri, atau anak yang berusia minimal 18 tahun). Sedangkan sampel yang diambil dalam penelitian ini sebanyak 100 responden masyarakat muslim kota Yogyakarta.

\section{b. Variabel}

Religiusitas adalah sifat yang membentuk pribadi dan sikap seseorang dengan ajaran agama dalam kehidupannya yang bersifat individual, subyektif dan kompleks. Religiusitas diukur dengan Islamic Behavioral Religiosity Scale (Youssef et al., 2011) yaitu: 1) Doktrin Islam terkait dengan pengetahuan Aqidah dan lima pilar agama. 2) Religiusitas Intrinsik terkait perilaku yang terkait langsung dengan pokok agama (Fiqh muamalat dan sembahyang di masjid). 3) Religiusitas Ekstrinsik terkait dengan perilaku religius yang terlaksana demi tujuan-tujuan sosial yang diinginkan.

Perilaku beramal (Charitable behavior) adalah aktivitas yang timbul karena adanya stimulus atau rangsangan yang berasal dari luar maupun dari dalam dirinya dengan respon memberikan bantuan kepada masyarakat yang membutuhkan. Perilaku beramal dapat diukur dengan

Pengaruh Religiusitas konsep beramal yang diproksikan dalam jumlah rupiah yang digunakan responden untuk beramal (Alawiyah:2009), intensitas responden dalam beramal (Machrus dan Purwono: 2010) dan teori bentuk-bentuk perilaku beramal dalam Islam yaitu: zakat, infak, sadaqah, dan wakaf (Veen, 2009 ; Lambaraa dan Riener, 2012 ; Martens, 2010; Qardhawi: 1997).

Instrumen dalam penelitian ini adalah Religiusitas dan perilaku untuk mengetahui pengaruh religiusitas terhadap perilaku beramal masyarakat. Instrumen tersebut dikembangkan dan dibuat dalam bentuk 
pertanyaan-pertanyaan yang relevan dalam bentuk angket. Angket yang digunakan dalam penelitian ini merupakan angket terbuka, yaitu angket yang diisi sesuai dengan jawaban yang dirasakan oleh responden. Adapun indikator dan kisi-kisi yang berkaitan dengan penelitian ini adalah sebagai berikut:

Tabel 1

Kisi-kisi dan Pengembangan Angket

\begin{tabular}{|c|l|c|c|}
\hline Variabel & \multicolumn{1}{|c|}{ Indikator } & \multicolumn{1}{c|}{ Sumber } & Items \\
\hline $\begin{array}{c}\text { Religiusitas } \\
(\mathrm{X})\end{array}$ & $\begin{array}{l}\text { 1. Religiusitas Intrinsik } \\
\text { 2. Doktrin Islam } \\
\text { 3. Religiusitas Ekstrinsik }\end{array}$ & Youssef et.,al (2011) & $\begin{array}{c}9-21 \\
22-29\end{array}$ \\
\hline $\begin{array}{c}\text { Perilaku } \\
\text { Beramal (Y) }\end{array}$ & $\begin{array}{l}\text { Bentuk Beramal dalam } \\
\text { Islam }\end{array}$ & $\begin{array}{c}\text { Veen (2009) } \\
\text { Lambaraa dan Riener, } \\
(2012)\end{array}$ & 10 \\
\cline { 2 - 4 } & $\begin{array}{c}\text { Intensitas Beramal } \\
\text { Qardhawi (1997) }\end{array}$ & 11 \\
\cline { 2 - 4 } & $\begin{array}{l}\text { Machrus dan } \\
\text { Jumlah Uang yang (2010) } \\
\text { digunakan untuk Beramal }\end{array}$ & Alawiyah (2009) & $12-15$ \\
\hline
\end{tabular}

Setiap alternatif jawaban dari variabel diberi skor untuk mengetahui data dalam bentuk kuantitatif, maka perlu diadakan penilaian pada tiap-tiap alternatif jawaban. Untuk mendapatkan hasil yang signifikan, penulis menggunakan alat ukur angket berupa continuous rating scale yang berupa jawaban terbuka dengan skala antara 0 (paling rendah) dan 10 (paling tinggi).

Selanjutnya dari pengembangan instrumen tersebut, dilakukan uji validitas dan realibilitas terhadap variabel-variabel tersebut untuk mengetahui apakah pengukuran yang dibuat valid dan reliabel atau tidak. Dalam pengolahan data statistiknya, penyusun menggunakan SPSS versi 17.0.

\section{c. Rancangan Analisis Data}

Dalam penelitian ini, data yang diperoleh diuraikan serta dianalisa untuk memperoleh gambaran yang jelas dari hasil jawaban responden melalui kuisioner. Data mentah yang didapatkan oleh penulis di lapangan kemudian diolah dengan menggunakan rumus-rumus statistik yang sudah ada. Analisis data yang digunakan dalam penelitian ini adalah analisis regresi sederhana karena hanya terdiri dari satu variabel independen dan satu variabel dependen. Sebelum melakukan analisis regresi sederhana, maka perlu dilakukan uji deskriptif dan uji asumsi klasik.

\section{Hasil}

Berikut analisis deskriptif responden masyarakat kota Yogyakarta yang meliputi: 1) Jenis kelamin, 2) Usia, 3) Pendidikan terakhir, 4) Pekerjaan saat ini, 5) Status Pernikahan, 6) Pendapatan perbulan, 7) Bentuk beramal, 8) Intensitas beramal, 9) Jumlah uang yang digunakan untuk Infak 10) Jumlah uang yang digunakan untuk shadaqah, 11) Jumlah uang yang digunakan untuk Zakat dan 12) Jumlah uang yang digunakan untuk Wakaf.

Sri

Maulida 
Berdasarkan data yang diperoleh dari proses tabulasi frekuensi, karakteristik responden berdasarkan jenis kelamin ditunjukkan pada tabel 2 berikut:

Tabel 2

Karakteristik Responden Berdasarkan Jenis Kelamin

\begin{tabular}{|l|c|c|}
\hline Keterangan & Jumlah & $\begin{array}{c}\text { Persentase } \\
\mathbf{( \% )}\end{array}$ \\
\hline Laki-Laki & 45 & 45,0 \\
\hline Perempuan & 55 & 55,0 \\
\hline Total & $\mathbf{1 0 0}$ & $\mathbf{1 0 0 , 0}$ \\
\hline
\end{tabular}

Sumber: data primer diolah (2013)

Berdasarkan tabel 2 diatas, dapat diketahui bahwa mayoritas responden dalam penelitian ini berjenis kelamin laki-laki yaitu sebanyak 45 orang $(45,0 \%)$. Sedangkan sisanya yang berjumlah 55 orang $(55,0 \%)$ adalah berjenis kelamin perempuan.

Berdasarkan data yang diperoleh dari proses tabulasi frekuensi, karakteristik responden berdasarkan usia ditunjukkan pada tabel 3 berikut:

Tabel 3

Karakteristik Responden

Berdasarkan Usia

\begin{tabular}{|l|c|c|}
\hline \multicolumn{1}{|c|}{ Keterangan } & Jumlah & $\begin{array}{c}\text { Persentase } \\
(\mathbf{\%})\end{array}$ \\
\hline 18 s/d 30 tahun & 26 & 26,0 \\
\hline 31 s/d 40 tahun & 31 & 31,0 \\
\hline 41 s/d 50 tahun & 43 & 43,0 \\
\hline Total & $\mathbf{1 0 0}$ & $\mathbf{1 0 0 , 0}$ \\
\hline
\end{tabular}

Sumber: data primer diolah (2013)

Berdasarkan tabel 3 diatas, dapat diketahui bahwa mayoritas responden dalam penelitian ini yang berumur antara 41-50 tahun yaitu sebanyak 43 orang $(43,0 \%)$. Sedangkan yang berumur antara $31-40$ tahun berjumlah 31 orang (31,0\%). Sedangkan sisanya yang berumur $18 \mathrm{~s} / \mathrm{d} 30$ tahun berjumlah 26 orang $(26,00 \%)$.

Berdasarkan data yang diperoleh dari proses tabulasi frekuensi, karakteristik responden berdasarkan pendidikan terakhir ditunjukkan pada tabel 4 berikut :

Tabel 4

Karakteristik Responden

Pendidikan Terakhir

Pengaruh

Religiusitas

\begin{tabular}{|l|c|c|}
\hline \multicolumn{1}{|c|}{ Keterangan } & Jumlah & $\begin{array}{c}\text { Persentase } \\
\mathbf{( \% )}\end{array}$ \\
\hline SMA & 34 & 34,0 \\
\hline Diploma & 18 & 18,0 \\
\hline Sarjana & 45 & 45,0 \\
\hline Pascasarjana & 3 & 3,0 \\
\hline Total & $\mathbf{1 0 0}$ & $\mathbf{1 0 0 , 0}$ \\
\hline \multicolumn{2}{|l}{ Sumber: data primer diolah (2013) }
\end{tabular}


Berdasarkan tabel 4 diatas diketahui bahwa responden dalam penelitian sebagian besar pendidikan terakhir adalah Sarjana yaitu berjumlah 45 orang $(45,0 \%)$. kemudian responden lulusan SMA berjumlah 34 orang $(34,0 \%)$, lulusan diploma berjumlah 18 orang $(18,0 \%)$, dan lulusan pasasarjana berjumlah 3 orang $(3,0 \%)$.

Berdasarkan data yang diperoleh dari proses tabulasi frekuensi, karakteristik responden berdasarkan jenis pekerjaan ditunjukkan pada tabel 5 berikut:

\section{Tabel 5}

Karakteristik Responden

Berdasarkan Jenis Pekerjaan

\begin{tabular}{|l|c|c|}
\hline \multicolumn{1}{|c|}{ Keterangan } & Jumlah & $\begin{array}{c}\text { Persentase } \\
\mathbf{( \% )}\end{array}$ \\
\hline Pelajar/Mahasiswa & 4 & 4,0 \\
\hline PNS & 72 & 72,0 \\
\hline Pegawai Swasta & 13 & 13,0 \\
\hline Wirausaha & 10 & 10,0 \\
\hline Lain-lain & 1 & 1,0 \\
\hline Total & $\mathbf{1 0 0}$ & $\mathbf{1 0 0 , 0}$ \\
\hline
\end{tabular}

Sumber: data primer diolah (2013)

Berdasarkan tabel 5 diatas diketahui bahwa mayoritas responden dalam penelitian ini adalah PNS sebanyak 72 orang $(72,0 \%)$. Sedangkan yang bekerja sebagai Pegawai Swasta berjumlah 13 orang $(13,0 \%)$, Wirausaha 10 orang (10,00\%), Pelajar/Mahasiswa berjumlah 4 orang $(4,0 \%)$. Sedangkan sisanya pekerjaan lain yakni berjumlah 1 orang $(2,00 \%)$. Berdasarkan data yang diperoleh dari proses tabulasi frekuensi, karakteristik responden berdasarkan jenis pekerjaan ditunjukkan pada tabel 6 berikut:

Tabel 6

Karakteristik Responden

Berdasarkan Status Pernikahan

\begin{tabular}{|l|c|c|}
\hline \multicolumn{1}{|c|}{ Keterangan } & Jumlah & $\begin{array}{c}\text { Persentase } \\
\mathbf{( \% )}\end{array}$ \\
\hline Belum Menikah & 20 & 20,0 \\
\hline Menikah & 75 & 75,0 \\
\hline Janda/Duda & 5 & 5,0 \\
\hline Total & $\mathbf{1 0 0}$ & $\mathbf{1 0 0 , 0}$ \\
\hline
\end{tabular}

Sumber: data primer diolah (2013)

Berdasarkan tabel 6 diatas diketahui bahwa mayoritas responden dalam penelitian ini berstatus menikah sebanyak 75 orang $(75,0 \%)$ dan yang berstatus belum menikah berjumlah 25 orang $(25,0 \%)$. Sisanya berjumlah 5 orang $(5,0 \%)$ orang berstatus Janda/Duda.

Berdasarkan data yang diperoleh dari proses tabulasi frekuensi, karakteristik responden berdasarkan jenis pekerjaan ditunjukkan pada tabel 7 berikut:

Sri

Maulida

6 
Tabel 7

Karakteristik Responden

Berdasarkan Jumlah Pendapatan Per Bulan

\begin{tabular}{|l|c|c|}
\hline \multicolumn{1}{|c|}{ Keterangan } & Jumlah & $\begin{array}{c}\text { Persentase } \\
(\mathbf{\%})\end{array}$ \\
\hline$<$ Rp1000.000 & 8 & 8,0 \\
\hline Rp1000.000-3.000.000 & 57 & 57,0 \\
\hline$>$ Rp3.000.000-5.000.000 & 32 & 32,0 \\
\hline > Rp5.000.000 & 3 & 3,0 \\
\hline Total & $\mathbf{1 0 0}$ & $\mathbf{1 0 0 , 0}$ \\
\hline
\end{tabular}

Sumber: data primer diolah (2013)

Berdasarkan tabel 7 diatas diketahui bahwa mayoritas pendapatan responden dalam penelitian ini Rp1.000.000 s/d 3.000.000 sebanyak 57 orang $(57,0 \%)$. Sedangkan yang mempunyai pendapatan lebih dari Rp3.000.000 s/d 5.000 .000 berjumlah 32 orang (32,0\%), pendapatan yang kurang dari Rp1.000.000 berjumlah 8 orang $(8,00 \%)$. Sedangkan sisanya yakni berjumlah 3 orang $(3,0 \%)$ mempunyai pendapatan lebih dari Rp5.000.000.

Berdasarkan data yang diperoleh dari proses tabulasi frekuensi, karakteristik responden berdasarkan bentuk beramal ditunjukkan pada tabel 8 berikut:

Tabel 8

Karakteristik Responden

Berdasarkan Bentuk Beramal

\begin{tabular}{|l|c|c|}
\hline \multicolumn{1}{|c|}{ Keterangan } & Jumlah & $\begin{array}{c}\text { Persentase } \\
\mathbf{( \% )}\end{array}$ \\
\hline Zakat & 6 & 6,0 \\
\hline Zakat dan Infak & 23 & 23,0 \\
\hline Zakat, Infak dan Shadaqah & 47 & 47,0 \\
\hline Zakat, Infak, Shadaqah dan Wakaf & 24 & 24,0 \\
\hline Total & $\mathbf{1 0 0}$ & $\mathbf{1 0 0 , 0}$ \\
\hline
\end{tabular}

Sumber: data primer diolah (2013)

Berdasarkan tabel 8 diatas diketahui bahwa mayoritas responden beramal dalam bentuk Zakat, Infak dan shadaqah sebanyak 47 orang $(47,0 \%)$. Sedangkan yang beramal dalam bentuk Zakat, Infak, Shadaqah dan Wakaf berjumlah 24 orang $(24,0 \%)$, responden yang beramal dalam bentuk Zakat dan Infak berjumlah 23 orang $(23,0 \%)$. Sedangkan sisanya yakni berjumlah 6 orang $(6,0 \%)$ hanya beramal dalam bentuk zakat.

Berdasarkan data yang diperoleh dari proses tabulasi frekuensi, karakteristik responden berdasarkan intensitas beramal ditunjukkan pada

Pengaruh tabel 9 berikut:

Religiusitas 
Tabel 9

Karakteristik Responden

Berdasarkan Intensitas Beramal

\begin{tabular}{|l|c|c|}
\hline \multicolumn{1}{|c|}{ Keterangan } & Jumlah & $\begin{array}{c}\text { Persentase } \\
\mathbf{( \% )}\end{array}$ \\
\hline Kurang dari 5 kali & 46 & 46,0 \\
\hline 5-10 kali & 35 & 35,0 \\
\hline 11-15 kali & 11 & 11,0 \\
\hline Lebih dari 15 kali & 8 & 8,0 \\
\hline Total & $\mathbf{1 0 0}$ & $\mathbf{1 0 0 , 0}$ \\
\hline
\end{tabular}

Sumber: data primer diolah (2013)

Berdasarkan tabel 9 diatas diketahui bahwa mayoritas responden beramal kurang dari lima kali sebanyak 46 orang $(46,0 \%)$. Sedangkan yang beramal lima sampai sepuluh kali berjumlah 35 orang $(35,0 \%)$ dan responden yang beramal 11-15 kali berjumlah 11 orang $(11,00 \%)$. Sedangkan sisanya yakni berjumlah 8 orang $(8,0 \%)$ beramal lebih dari 15 kali dalam satu bulan.

Berdasarkan data yang diperoleh dari proses tabulasi frekuensi, karakteristik responden berdasarkan Jumlah Uang yang digunakan untuk Infak ditunjukkan pada tabel 10 berikut:

Tabel 10

Karakteristik Responden

Berdasarkan Jumlah Uang yang digunakan untuk Infak

\begin{tabular}{|l|c|c|}
\hline \multicolumn{1}{|c|}{ Keterangan } & Jumlah & $\begin{array}{c}\text { Persentase } \\
\mathbf{( \% )}\end{array}$ \\
\hline Kurang dari Rp10.000 & 22 & 22,0 \\
\hline Rp10.000 s/d Rp50.000 & 52 & 52,0 \\
\hline Lebih dari Rp50.000 s/d Rp100.000 & 15 & 15,0 \\
\hline Lebih dari Rp100.000 & 11 & 11,0 \\
\hline Total & $\mathbf{1 0 0}$ & $\mathbf{1 0 0 , 0}$ \\
\hline
\end{tabular}

Sumber: data primer diolah (2013)

Berdasarkan tabel 10 diatas diketahui bahwa mayoritas responden menggunakan uang dalam berinfak sebesar Rp10.000 s/d Rp50.000 sebanyak 52 orang (52,0\%). Sedangkan yang menggunakan uang untuk berinfak kurang dari Rp10.000 berjumlah 22 orang $(22,0 \%)$ dan menggunakan uang untuk berinfak lebih dari Rp50.000 s/d Rp100.000 berjumlah 15 orang $(15,0 \%)$. Sedangkan sisanya yakni berjumlah 11 orang 11,0\%) menggunakan uang untuk berinfak lebih dari Rp100.000.

Berdasarkan data yang diperoleh dari proses tabulasi frekuensi, karakteristik responden berdasarkan Jumlah Uang yang digunakan untuk Shadaqah ditunjukkan pada tabel 18 berikut:

Sri

Maulida 
Tabel 11

Karakteristik Responden

Berdasarkan Jumlah Uang yang digunakan untuk Shadaqah

\begin{tabular}{|l|c|c|}
\hline \multicolumn{1}{|c|}{ Keterangan } & Jumlah & $\begin{array}{c}\text { Persentase } \\
\mathbf{( \% )}\end{array}$ \\
\hline Kurang dari Rp10.000 & 24 & 24,0 \\
\hline Rp10.000 s/d Rp50.000 & 49 & 49,0 \\
\hline Lebih dari Rp50.000 s/d Rp100.000 & 15 & 15,0 \\
\hline Lebih dari Rp100.000 & 12 & 12,0 \\
\hline Total & $\mathbf{1 0 0}$ & $\mathbf{1 0 0 , 0}$ \\
\hline
\end{tabular}

Sumber: data primer diolah (2013)

Berdasarkan tabel 11 diatas diketahui bahwa mayoritas responden menggunakan uang yang digunakan untuk shadaqah sebesar Rp10.000 s/d Rp50.000 sebanyak 49 orang (49,0\%). Sedangkan yang yang menggunakan uang yang digunakan untuk shadaqah Kurang dari Rp10.000 berjumlah 24 orang $(24,0 \%)$, menggunakan uang yang digunakan untuk shadaqah lebih dari Rp50.000 s/d Rp100.000 berjumlah 15 orang (15,0\%). Sedangkan sisanya yakni berjumlah 12 orang $(12,0 \%)$ menggunakan uang yang digunakan untuk shadaqah lebih dari Rp100.000.

Berdasarkan data yang diperoleh dari proses tabulasi frekuensi, karakteristik responden berdasarkan Jumlah Uang yang digunakan untuk zakat ditunjukkan pada tabel 12 berikut:

Tabel 12

Karakteristik Responden

Berdasarkan Jumlah Uang yang digunakan untuk Zakat

\begin{tabular}{|l|c|c|}
\hline \multicolumn{1}{|c|}{ Keterangan } & Jumlah & $\begin{array}{c}\text { Persentase } \\
\mathbf{( \% )}\end{array}$ \\
\hline Tidak Berzakat & 1 & 1,0 \\
\hline Kurang dari Rp50.000 & 31 & 31,0 \\
\hline Rp50.000 s/d Rp100.000 & 48 & 48,0 \\
\hline Lebih dari Rp100.000 s/d Rp500.000 & 15 & 15,0 \\
\hline Lebih dari Rp500.000 & 5 & 5,0 \\
\hline Total & $\mathbf{1 0 0}$ & $\mathbf{1 0 0 , 0}$ \\
\hline
\end{tabular}

Sumber: data primer diolah (2013)

Berdasarkan tabel 12 diatas diketahui bahwa mayoritas responden menggunakan uang yang digunakan untuk Zakat sebesar Rp50.000 s/d Rp100.000 sebanyak 48 orang (48,0\%). Sedangkan yang yang menggunakan uang yang digunakan untuk Zakat Kurang dari Rp50.000 berjumlah 31 orang $(31,0 \%)$, menggunakan uang yang digunakan untuk Zakat Lebih dari Rp100.000 s/d Rp500.000 berjumlah 15 orang (15,0\%). Kemudian

Pengaruh Religiusitas responden yang menggunakan uang untuk Zakat Lebih dari Rp500.000 sebanyak 5 orang $(5,0 \%)$. Sedangkan sisanya yakni berjumlah 1 orang $(1,0 \%)$ tidak berzakat.

Berdasarkan data yang diperoleh dari proses tabulasi frekuensi, karakteristik responden berdasarkan Jumlah Uang yang digunakan untuk Wakaf ditunjukkan pada tabel 13 berikut: 
Tabel 13

Karakteristik Responden

Berdasarkan Jumlah Uang yang digunakan untuk Wakaf

\begin{tabular}{|l|c|c|}
\hline \multicolumn{1}{|c|}{ Keterangan } & Jumlah & $\begin{array}{c}\text { Persentase } \\
\mathbf{( \% )}\end{array}$ \\
\hline Tidak Berwakaf & 36 & 36,0 \\
\hline Kurang dari Rp50.000 & 40 & 40,0 \\
\hline Rp50.000 s/d Rp100.000 & 17 & 17,0 \\
\hline Lebih dari Rp100.000 s/d Rp500.000 & 7 & 7,0 \\
\hline Total & $\mathbf{1 0 0}$ & $\mathbf{1 0 0 , 0}$ \\
\hline
\end{tabular}

Sumber: data primer diolah (2013)

Berdasarkan tabel 13 diatas diketahui bahwa mayoritas responden menggunakan uang yang digunakan untuk wakaf dalam satu bulan Kurang dari Rp50.000 sebanyak 40 orang (40,0\%). Sedangkan yang tidak berwakaf dalam satu bulan terakhir berjumlah 36 orang $(36,0 \%)$, responden menggunakan uang yang digunakan untuk wakaf dalam satu bulan Rp50.000 s/d Rp100.000 berjumlah 17 orang (17,0\%). Sedangkan sisanya yakni berjumlah 7 orang $(7,0 \%)$ menggunakan uang yang digunakan untuk wakaf dalam satu bulan Lebih dari Rp100.000 s/d Rp500.000.

Berdasarkan hasil penyebaran kuesioner diperoleh juga data mengenai tanggapan responden terhadap variabel yang digunakan dalam penelitian ini. Adapun data selengkapnya adalah sebagai berikut:

\section{a. Tanggapan Responden Terhadap Variabel Religiusitas}

Skor minimum : :126

Skor maksimum : $: 257$

Nilai SD $(\sigma) \quad: 22,793$

Mean teoritis $(\mu) \quad: 215,04$

Dengan klasifikasi

Tinggi

$: x \geq 215,04+1(22,793)$ atau $x \geq 237,833$

Cukup

: 215,04- $1(22,793) \leq x<215,04+1(22,793)$ atau $192,25 \leq x$

$<237,8$

Rendah

: $x \leq 215,04-1(22,793)$ atau $x \leq 192,25$

Tabel 14

Tanggapan Responden Terhadap Variabel Religiusitas

\begin{tabular}{|l|c|c|}
\hline \multicolumn{1}{|c|}{ Tanggapan } & Jumlah & Persentase (\%) \\
\hline Tinggi & 16 & 16,0 \\
\hline Cukup & 69 & 69,0 \\
\hline Rendah & 15 & 15,0 \\
\hline Jumlah & $\mathbf{1 0 0}$ & $\mathbf{1 0 0 , 0}$ \\
\hline
\end{tabular}

Sumber : Data primer diolah 2013

Berdasarkan tabel 14 di atas diketahui bahwa tanggapan responden terhadap variabel religiusitas yang termasuk dalam kategori tinggi sebanyak 16 orang $(16,0 \%)$, kategori cukup sebanyak 69 orang $(69,0 \%)$, dan sisanya sebanyak 15 orang $(15,0 \%)$ termasuk dalam kategori rendah. Berdasarkan kondisi tersebut, hal ini menunjukkan bahwa tanggapan responden terhadap variabel religiusitas termasuk dalam kategori cukup.

Sri

Maulida 


\section{b. Tanggapan Responden Terhadap Perilaku Beramal}

Skor minimum : :7

Skor maksimum $\quad: 21$

Nilai SD $(\sigma) \quad: 3,406$

Mean teoritis $(\mu) \quad: 12,12$

Dengan klasifikasi

Baik

$: x \geq 12,12+1(3,406)$ atau $x \geq 15,526$

Cukup

: $12,12-1(3,406) \leq x<12,12+1(3,406)$ atau $8,714 \leq x<$ 15,526

Buruk

Tabel 15

Tanggapan Responden

Perilaku beramal

\begin{tabular}{|l|c|c|}
\hline \multicolumn{1}{|c|}{ Tanggapan } & Jumlah & Persentase (\%) \\
\hline Baik & 6 & 6,0 \\
\hline Cukup & 92 & 92,0 \\
\hline Buruk & 2 & 2,0 \\
\hline Jumlah & $\mathbf{1 0 0}$ & $\mathbf{1 0 0 , 0}$ \\
\hline
\end{tabular}

Sumber : Data primer diolah 2013

Berdasarkan tabel 15 di atas diketahui bahwa tanggapan responden terhadap variabel perilaku beramal yang termasuk dalam kategori baik sebanyak 6 orang $(6,0 \%)$, kategori cukup sebanyak 92 orang $(92,0 \%)$, dan sisanya sebanyak 2 orang $(2,0 \%)$ termasuk dalam kategori buruk. Berdasarkan kondisi tersebut, hal ini menunjukkan bahwa tanggapan responden terhadap variabel perilaku beramal termasuk dalam kategori cukup.

\section{Uji Asumsi Klasik}

Uji asumsi ini digunakan untuk apakah dalam suatu model regresi terjadi ketidaksamaan varian dari residual dalam suatu pengamatan ke pengamatan yang lain, jika varian dari residual dalam satu pengamatan ke pengamatan yang lain tetap maka disebut homoskedostisitas. Jika varian berbeda disebut heteroskedostisitas

Pengaruh Religiusitas

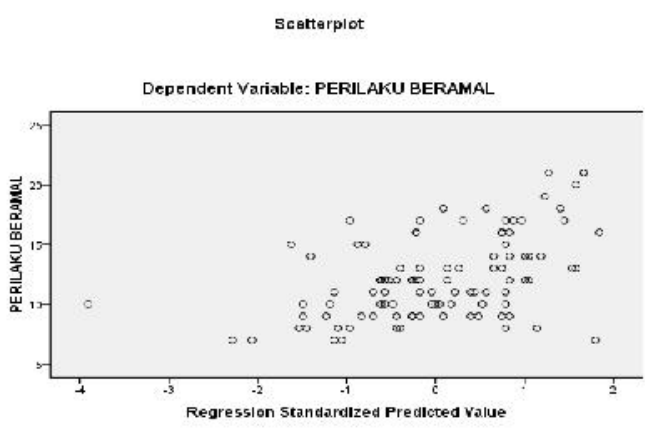

Gambar 1

\section{Hasil Uji Heteroskedastisitas}

Berdasarkan gambar di atas dapat diketahui bahwa tidak ada pola yang jelas serta titik-titik menyebar maka tidak terjadi heteroskedastisitas. 


\section{Uji Autokorelasi}

Autokorelasi yaitu korelasi secara urutan pengamatan dalam waktu ke waktu, untuk memeriksa adanya autokorelasi digunakan uji durbin watson. Mendeteksi autokorelasi dengan menggunakan nilai Durbin Watson dibandingkan dengan menggunakan tabel Durbin Watson (dl dan du). Kriteria jika du < dhitung < 4-du maka tidak terjadi autokorelasi (Sujarweni, 2006: 180).

Hasil uji autokorelasi menunjukkan bahwa nilai Durbin Watson adalah sebesar 2,010. Sedangkan nilai Durbin Watson dalam tabel DW $(\mathrm{k}, \mathrm{n})$ $(2,100)$ diperoleh nilai du sebesar 1,715. Maka nilai autokorelasi diantara $1,715<2,010<2,285$. Jadi tidak terjadi autokorelasi.

\section{Analisis Regresi Linear Sederhana}

Analisis regresi linear sederhana berganda ini digunakan untuk mengetahui pengaruh variabel independen (Religiusitas) terhadap variabel dependen (Perilaku beramal). Adapun model statistik penelitian ini adalah sebagai berikut:

$\hat{\mathrm{Y}}=\mathrm{b} 0+\mathrm{b} 1 . \mathrm{X}$

Keterangan:

$$
\begin{array}{ll}
\mathrm{Y} & =\text { Perilaku beramal } \\
\mathrm{X} & =\text { Religiusitas } \\
\mathrm{b} 0 & =\text { Konstanta } \\
\mathrm{b} 1 & =\text { Koefisien Regresi }
\end{array}
$$

Setelah dilakukan perhitungan dengan menggunakan bantuan komputer pada program SPSS 17,0 diperoleh hasil yang tercantum dalam tabel berikut:

\section{Tabel 16}

Hasil Analisis Regresi Sederhana

\begin{tabular}{|c|c|c|c|c|}
\hline Variabel & $\begin{array}{c}\text { Koefisien } \\
\text { Regresi }\end{array}$ & $\begin{array}{c}\text { Standar } \\
\text { Error }\end{array}$ & t hitung & Sig. T \\
\hline Religiusitas & 0,069 & 0,013 & 5,186 & 0,000 \\
\hline Konstanta & 2,791 & & \\
R & 0,464 & & \\
R Square & 0,215 & & \\
F & 26,892 & & \\
Sig. F & 0,000 & & \\
\hline
\end{tabular}

Sumber : Data primer diolah 2013

Berdasarkan hasil perhitungan analisis regresi sederhana maka secara matematis dapat ditulis ke dalam persamaan sebagai berikut :

$\hat{Y}=2,791+0,069 . X$

Pada persamaan di atas ditunjukkan pengaruh variabel independen $(\mathrm{X})$ terhadap variabel dependen $(\mathrm{Y})$. Adapun arti dari koefisien regresi tersebut adalah sebagai berikut: a) Konstanta (b0) $=2,791$, artinya apabila variabel religiusitas tidak ada atau sama dengan nol maka religiusitas masyarakat kota Yogyakarta sebesar 2,791 dan b) Koefisien regresi b1 = 0,069, artinya apabila perilaku beramal yang berhubungan dengan religiusitas masyarakat kota Yogyakarta lebih baik, maka perilaku beramal

Sri

Maulida 
masyarakat kota Yogyakarta akan naik sebesar 0,069 dengan asumsi variabel lain tetap.

Pengujian Secara Individual (Uji t)

Uji t pada dasarnya menunjukkan seberapa jauh pengaruh satu variabel independen secara individual dalam menerangkan variasi variabel dependen.

Perumusan hipotesis nihil (Ho) dan hipotesis alternatif (Ha):

Ho : tidak terdapat pengaruh antara religiusitas (X1) terhadap perilaku beramal $(\mathrm{Y})$

Ha: terdapat pengaruh antara religiusitas (X1) terhadap perilaku beramal $(\mathrm{Y})$

Pengambilan keputusan dengan taraf signifikansi 5\% ditentukan sebagai berikut:

Bila nilai signifikansi $>0,05$, maka Ho diterima

Bila nilai signifikansi $<0,05$, maka Ho ditolak

Berdasarkan hasil pengujian dapat diketahui nilai $\mathrm{t}$ hitung sebesar 5,186 dengan sig. $t$ sebesar $0,000(p<0,05)$, sehingga keputusannya menolak Ho dan menerima Ha. Berarti ada pengaruh yang signifikan antara variabel religiusitas terhadap perilaku beramal.

\section{Koefisien Determinasi (R2)}

Koefisien determinasi $\left(\mathrm{R}^{2}\right)$ digunakan sebagai alat analisis untuk menunjukkan besarnya kontribusi varian variabel independen (Religiusitas) terhadap varian variabel dependen yaitu perilaku beramal. Dari hasil pengujian diperoleh nilai koefisien deteminasi $\left(R^{2}\right)$ sebesar 0,215 yang berarti kontribusi varian yang diberikan oleh variabel religiusitas terhadap perilaku beramal adalah sebesar 21,5\%, sedangkan sisanya sebesar 78,5\% dipengaruhi oleh varian lain di luar model.

\section{Pembahasan}

Berdasarkan hasil analisis deskriptif responden, diperoleh responden penelitian ini berjenis kelamin laki-laki sebanyak 45 orang atau $45 \%$ dan perempuan sebanyak 55 orang atau $55 \%$, rata-rata berumur antara 41-50 tahun sebanyak 43 orang atau $43 \%$, pendidikan terahir responden didominasi oleh sarjana sebanyak 45 orang atau $45 \%$, pekerjaan responden didominasi oleh PNS sebanyak 72 orang atau 72\%, status pernikahan responden rata-rata adalah menikah yaitu sebanyak 75 orang atau $75 \%$, rata-rata pendapatan per bulan responden adalah Rp1.000.000-3.000.000 sebanyak 57 orang atau $57 \%$. Berdasarkan hasil tersebut, responden dalam penelitian ini mempunyai pendidikan yang tinggi, mempunyai pekerjaan yang layak serta mempunyai status menikah dengan pendapatan yang diatas Upah Minimum Regional (UMR) Yogyakarta. Sehingga penyusun menilai pekerjaan, pendidikan, pendapatan dan status pernikahan

Pengaruh Religiusitas responden dalam penelitian ini dapat mendukung penelitian yang dilakukan, karena rata-rata responden berada di taraf kehidupan yang baik.

Rata-rata responden beramal dalam bentuk zakat, infak dan shadaqah yaitu sebanyak 47 orang atau $47 \%$, rata-rata responden beramal dalam satu bulan 5-10 kali yaitu sebanyak 35 orang atau $35 \%$, rata-rata jumlah uang yang digunakan responden untuk infak dalam satu bulan Rp10.000-Rp50.000 yaitu sebanyak 52 orang atau 52\%, rata-rata jumlah 
uang yang digunakan responden untuk shadaqah dalam satu bulan Rp10.000-Rp50.000 yaitu sebanyak 49 orang atau $49 \%$, rata-rata jumlah uang yang digunakan responden untuk zakat dalam satu bulan Rp50.000Rp100.000 yaitu sebanyak 48 orang atau 48\%, rata-rata jumlah uang yang digunakan responden untuk wakaf dalam satu bulan kurang dari Rp50.000 yaitu sebanyak 40 orang atau $40 \%$. Hasil analisis ini menunjukkan bahwa responden beramal dalam bentuk zakat, infak dan shadaqah serta lebih banyak menggunakan uang untuk beramal dalam bentuk tersebut sedangkan untuk wakaf masih sedikit.

Berdasarkan analisis deskriptif variabel diperoleh hasil bahwa tanggapan responden terhadap variabel perilaku beramal termasuk dalam kategori cukup baik yaitu sebanyak 69 orang atau sebesar 69,0\%. Tanggapan responden terhadap variabel religiusitas termasuk dalam kategori cukup baik yaitu sebanyak 92 orang atau sebesar $92,0 \%$.

Selanjutnya hasil olah data penelitian menunjukkan bahwa variabel religiusitas berpengaruh signifikan terhadap perilaku beramal dimana tingkat signifikasi sebesar 0,000 yang lebih kecil dari 0,05. Hasil ini sesuai dengan hipotesis yang diformulasikan dan mendukung penelitian yang telah dilakukan oleh Reitsma, Scheepers, dan Grotenhuis (2006) dan penelitian Awaliyah (2009). Kemudian variabel religiusitas memiliki pengaruh positif terhadap perilaku beramal yang dilihat dari nilai $R$, semakin besar nilai $\mathrm{R}$ maka pengaruh religiusitas terhadap perilaku beramal semakin baik dalam penelitian ini nilai korelasi sebesar 0,464 sedangkan untuk melihat kontribusi dilihat dari nilai R2 semakin besar nilai R2 maka kontribusinya semakin besar, hasil penelitian menunjukkan bahwa nilai R2 sebesar 0,215 atau 21,5\%. Jadi kontribusi variabel religiusitas terhadap perilaku beramal tidak mencapai $50 \%$.

\section{Keterbatasan dan penelitian selanjutnya}

Hasil penelitian yang menunjukkan bahwa religiusitas berpengaruh signifikan terhadap perilaku beramal, dimana hasil penelitian menunjukkan bahwa variabel religiusitas memiliki kontribusi sebesar $21,5 \%$. Berdasarkan hasil ini diketahui bahwa kontribusi religiusitas terhadap perilaku beramal masih kecil dibandingkan dengan variabel lain diluar model penelitian, untuk itu diharapkan bagi pihak yang berkaitan dengan penelitian ini baik sebagai mahasiswa, dosen, ustadz, pihak praktisi maupun akademisi dapat melakukan sosialisasi dan pemberian informasi seperti ceramah mengenai perilaku beramal yang lebih intens agar masyarakat kota Yogyakarta lebih memahami dan memiliki pengetahuan tentang perilaku beramal tersebut sehingga mempunyai kesadaran untuk menggunakan uangnya untuk beramal.

Melihat nilai $\mathrm{R}$ square yang besarnya hanya mencapai 0,215 artinya variabel tersebut mempengaruhi varibel dependen sebesar 21,5\%. Dimana $78,5 \%$ dipengaruhi variabel lain diluar variabel yang dipakai dalam penelitian ini. Maka bagi penyusun selanjutnya, jika ingin melakukan penelitian yang identik dengan tema penelitian ini, diharapkan untuk menggunakan metode yang berbeda dalam pengukuran perilaku beramal. Metode yang disarankan oleh penyusun adalah dengan cara wawancara yang dilakukan dengan tatap muka atau langsung dan pertanyaan yang ada dalam perilaku beramal dibacakan oleh peneliti. Jika responden yang

\section{Sri \\ Maulida}


diwawancarai memberikan informasi yang kurang jelas, maka penyusun dapat memeriksa jawaban tersebut. Lebih lanjut, sebaiknya menggunakan populasi yang lebih khusus agar hasil penelitian dapat direalisasikan dengan baik.

Pengaruh

Religiusitas 


\section{DAFTAR PUSTAKA}

Alawiyah, Tuti (2009), "Korelasi Perbuatan Beramal Dengan Besarnya Nominal Umat Islam Indonesia", Zakat \& Empowering Jurnal Pemikiran dan Gagasan- Vol II.

Lambarraa, Fatima, Gerhard Riener. (2012), On the Norms of Charitable Giving in Islam: A Field Experiment, Selected Paper prepared for presentation at the International Association of Agricultural Economists (IAAE) Triennial Conference, Foz do Iguaçu, Brazil, 1824 August, 2012.

Machrus, Hawa'im dan Urip Purwono. (2010), “Pengukuran Perilaku Berdasarkan Theory of Planned Behavior", Departemen Psikologi Kepribadian dan Sosial Fakultas Psikologi Universitas Airlangga, Jl.Dharmawangsa Dalam Selatan Surabaya. INSAN Vol. 12 No. 01. Martens, Silvia. (2010), "Theory and Practice of Islamic Charity in a NonMuslim Society: the Case of Switzerland", Institute for Islamic and Middle Eastern Studies,University of Bern.

PIRAC. (2007), Pola Dan Potensi Sumbangan Masyarakat. Survei Rumah Tangga di 11 Kota Besar.

Qardhawi, Yusuf. (1995), Kiat Islam Mengentaskan Kemiskinan, Jakarta : Gema Insani.

Reitsma, Jan, Peer Scheepers, Manfred Te Grotenhuis. (2006), "Dimensions Of Individual Religiosity And Charity:Cross National Effect Differences In European Countries?", Review OF Religious Research 2006, Volume 47(4), Pages 347-362.

Sujarweni, V. Wiratna. (2008), Belajar Mudah SPSS Untuk Penelitian, Yogyakarta: Penerbit

Veen, Rianne C. Ten. (2009), Charitable Giving in Islam, United Kingdom: Islamic Relief Worldwide.

Youssef, Mariam Abou; Wael Kortam; Ehab Abou-Aishand Noha ElBassiouny. (2011), "Measuring Islamic-Driven Buyer Behavioral Implications: A Proposed Market-Minded Religiosity Scale", Journal of American Science 7(8):728-741].(ISSN: 1545-1003).

Tim Penyusun BPS. 2010. www.bps.go.id. Diakses Pada Hari Rabu, 20 Februari 2013 pukul 11.36 WIB.

Potensi zakat pegawai baru terserap 30\%. 2012.

http://ramadhan.antaranews.com/berita/325270/potensi-zakatpegawai-baru-terserap-30. Diakses Pada Hari Jum'at, 20 September 2013 pukul 13.10 WIB.

Sensus Penduduk. 2010. Mayoritas Penduduk di Indonesia adalah Muslim.

Tersedia di http://sp2010.bps.go.id/index.php/site/tabel?tid=321.

Diakses pada hari Selasa 30 April 2013 pukul 11.36 WIB.

Sri

Maulida 